\title{
Stress among Teachers: A Theoretical Examination
}

\author{
Waqar M Parray ${ }^{1 *}$, Dr. Sanjay Kumar ${ }^{2}$, Dr. Purnima Awasthi ${ }^{3}$
}

\section{ABSTRACT}

The word 'Stress' is defined by the Oxford dictionary as "state of affair involving of demand on physical or mental energy". Stress is a state of mental tension and worry caused by problems in one's life, work, etc. Stress is a general term applied to various psychological (mental) and physiological (bodily) pressures experienced or felt by people throughout their lives. Hans Selye, one of the leading authorities on the concept of stress, described stress as "the rate of all wear and tear caused by life. Every one experience stress whether it is within the family, business, organization or any other economic activity. Stress is a big problem in our society. The main objective of this is to assess the level of stress of the teachers working in Universities, Secondary Schools, Elementary Schools, and teachers working in different organisations. Researchers have made all attempts to critically examine the studies conducted in the field of stress.

Keywords: Stress, Teachers, Theoretical Examination

Teaching profession has traditionally been regarded as low stress occupation (French, et.al., 1982) but during the past two decades the situation is somersaulted (Olivier \& Venter, 2003).Teaching is becoming a more challenging profession worldwide. Surveys conducted worldwide revealed widespread concern about the effects of stress on teachers' sense of wellbeing and their willingness to stay in the profession. Before 1970's, teaching was considered as as a noble profession. However, in the recent years, researches have proved that teaching profession is one of the stressful profession (Ravichandran \& Rajendran, 2007).

Now the question arises of why the job teachers shifted from low stress profession to high stress profession? Various reasons have been discussed in researches to address the question of why teachers are becoming more stressful. Some answers have also been supplied that teachers has to face different demands from school management, parents and society. At the same time, teachers are required acquire many new skills to cope effectively in a very fast changing society. They

\footnotetext{
${ }^{1}$ Research Scholar, Department of Psychology, Doctor Harisingh Gour University, Sagar, M. P. India

${ }^{2}$ Assistant Professor, Department of Psychology, Doctor Harisingh Gour University, Sagar, M. P. India

${ }^{3}$ Assistant Professor, Department of Psychology, Banaras Hindu University, India

*Responding Author

(C) 2016 I W Parrav, S Kumar, P Awasthi; licensee IJIP. This is an Open Access Research distributed under the terms of the Creative Commons Attribution License (http://creativecommons.org/licenses/by/2.0), which permits unrestricted use, distribution, and reproduction in any Medium, provided the original work is properly cited.
} 


\section{Stress among Teachers: A Theoretical Examination}

have to equip themselves in terms of creativity, innovations and critical thinking. Teachers are blindly criticized if they fail to provide knowledge and services to society according to expectations. The issue of stress among teachers is becoming as one of the serious problem where adequate attention is needed. Experiencing high level of stress could lead to various negative consequences such as poor performance, lack of commitment, lack of motivation and poor quality of classroom teaching. Thus, stress seems pervasive among all teachers working at different level in different institutions.

\section{Stress and University Teachers}

This section of this review covers the type, level, sources and remedies of the stress experienced by University teachers. Onifade (2000) conducted a research entitled determinants of occupational stress and coping strategies of physical education teachers. The concern of this study revealed those factors which stress physical education teachers in the performance of their job. The results from the study indicated that too many students and not enough physical education facilities/equipment was the most stressful factor.

Aggarwal (2012) in her study on self-efficacy as predictor of occupational stress among academic faculties of Punjab University and Guru Nanak Dev University” has explained the interactive and relative effects of self-efficacy on occupational stress of academic faculty. The findings indicated that self-efficacy is effective in predicting role insufficiency and role ambiguity. On the basis of her study she suggested that training workshops on self-efficacy will help the teachers to cope up with stress due to role insufficiency and role ambiguity.

Shikieri \& Musa (2012) studied the factors associated with occupational stress and their effects on organizational performance in a Sudanese University. They attempted to determine the factors associated with occupational stress and their relationship with organizational performance at one of the private universities in Sudan. Their research study depicted that on average the teacher's experienced high degree of job stress. Job stressors affected the general physical health, job satisfaction and work performance as well as commitment of the teachers negatively. The study recommended that the university needs to elevate the situation and resolve all the factors affecting the employees as per situation.

Nagra \& Arora (2013) conducted the research on occupational stress and health among teacher educators. They strived to find out the level of occupational stress and its relationship to health among the teacher educators in relation to their gender and marital status. The results of their study revealed that teacher educators experienced moderate level of occupational stress \& significant differences were indicated regarding occupational stress among teacher educators in relation to gender and marital status.

Sindhu (2014) conducted an empirical research entitled "a study on stressors among college teachers.” They analysed various stressors among college teachers by using various research

(C) The International Journal of Indian Psychology, ISSN 2348-5396 (e)| ISSN: 2349-3429 (p) | 89 


\section{Stress among Teachers: A Theoretical Examination}

tools. On the basis of the findings of the study the researcher has clearly concluded that the college teachers are affected by stress especially work Stress and also recommended that they must adapt some coping strategies for overcoming the stress.

Bhuvaneshwari (2013) conducted a case study on psychological and physical stress undergone by married women working in deferent teaching institutions. Researcher revealed that stress in married working women is caused due to long working hours, various family and official commitments, harassments and improper work life balance. Such type of stress leads to various problems such as prolonged headaches, hypertension and obesity. The researcher clearly concluded that Stress can be relieved from institutional support, balancing work and life by spending time with family, entertainments, yoga and rest.

Ghania, Ahmad \& Ibrahim (2014) studies the stress among special education teachers in Malaysia. They investigated the factors that contribute stress and level of occupational stress among special education teachers who are teaching in special education classes in the state of Penang, Malaysia. The results from their study revealed that pupil misbehaviour as the main source of teacher stress among special education teachers, followed by workload, time and resources difficulties, recognition, and interpersonal relationship.

Research on stress among academic and general staff of universities from across the globe indicates that the phenomenon of stress in universities is alarmingly widespread and increasing. From the above studies, their findings and recommendations it can be concluded that stress among university teachers is somehow similar at different levels of positions. Researchers have pointed out different stressors among university teachers.

Researchers have clearly pointed out the role of gender and marital status with regard to stress (Nagra \& Arora, 2013) while other researchers have indicated role insufficiency and role ambiguity as a factor of stress (Aggarwal, 2012). Apart from that some other has clearly concluded that university/ college are mostly affected by not other than work stress. When it comes to married working woman, some of the case studies revealed that the stress among this folk is because of long working hours, various family and official commitments, harassments and improper work life balance (Bhuvaneshwari, 2013). The consequences of such stressors may result in hypertension, depression, obesity and headache according to the study. Many working women in India are stuck in stress and depression.

This stress can be reduced by sharing their personal work with the family members and official works with the subordinates at work place. Infect long working hours induces stress in married working women, such stress can be reduced by giving number of breaks between the working hours and providing some refreshments for overcoming physical and mental tiredness during working time and also shifting timings can be framed to reduce the working hours. 


\section{Stress among Teachers: A Theoretical Examination}

Various other factors depicted by various studies are private jobs (teachers), scarcity of physical education facilities, equipments along with too many students and some of the studies also signified misbehaviour from the part of pupils / students as a main source of stress among teachers (Onifade, 2000; Ghania, Ahmad \& Ibrahim, 2014). The above data clearly indicates that too many students and not enough physical education facilities/equipment was the most stressful factor for the teachers.

In order to reduce stress, management can provide better facilities and necessary equipments. It is also necessary that physical education administrators must be aware of the many factors that are potential stressors on physical education teachers. Employees are valuable assets of the organisation and they increase the profitability of the institute. The university needs to elevate the situation and resolve all the factors affecting the employees. This could be achieved by constructing clear formal rules, policies and guidelines so that all the employees have to fulfil. In addition, the university could either increase the number of staff needed to perform the tasks and enrolled adequate number of students, increase the overall paid salaries to compensate for such stressors. Keeping above discussion into mind, we can conclude that different teachers face different levels of stress and this stress are caused by different reasons and originates from different sources.

\section{Stress and Secondary School Teachers}

This section of this review covers the type, level, sources and remedies of the stress experienced by secondary school teachers. Aftab \& Khatoon (2012) investigated the demographic differences and occupational stress of secondary school teachers. They examined the relationships of a set of independent variables (gender, qualification, teaching experience,) with occupational stress among secondary school teachers. Findings of the study revealed that nearly half of the secondary school teachers experience moderate level of stress in their job setting. Male teachers reported more occupational stress towards job than the females. They also found that revealed that trained graduate teachers experienced higher occupational stress than post-graduate teachers. Finally they revealed that teachers served for 6-10 years as teacher experienced highest level of stress while the teachers served for 0-5 years experienced least amount of stress.

Ekundayo \& Kolawole (2013) conducted study entitled "stress among secondary school teachers in Ekiti State, Nigeria”. They examined the various sources of stress among teachers of secondary schools in Ekiti State and also examined the coping strategies adapted by the teachers. The results revealed that poor working conditions, poor relations with super ordinates and late payment of salaries were major sources of stress. The study also revealed that managing one's time effectively is the main strategy for coping with stress.

Reddy \& Anuradha (2013) conducted a study on occupational stress of teachers working at higher secondary level. They revealed that around 88 percent of higher secondary teachers are 


\section{Stress among Teachers: A Theoretical Examination}

experiencing moderate and high levels of occupational stress. Researchers suggested some measures which could prove beneficial to teachers in coping with stress. The measures includes improve self esteem, build self confidence, develop a good sense of humour, practice yoga and meditation, exercise regularly, foster a supportive friend circle.

Kousar and Sohail (2014) conducted the research on occupational role stress (ORS) and health related quality of life among secondary school teachers (SST). They attempted to find out the role stressors among secondary school teachers and the relationship of occupational role stress to the health related quality of life of the teachers. They concluded that men S.S.T.s experienced more ORS than women S.S.T.s and also revealed that men S.S.T.s had poor physical health as compared to women S.S.T.s.

Manabete, John, Makinde \& Duwa (2016) conducted a research on job stress among school administrators and teachers in Nigerian secondary schools and technical colleges. They examined stress, job or workplace stress among teachers in Nigeria. Findings revealed that role ambiguity, poor relations with boss, work overload are the main sources of stress among teachers.

While concluding the above findings and results it is noteworthy to bring into notice various factors of stress identified by various researchers. Some of the researchers have revealed that poor working conditions, poor relationships and late payment of salaries as major sources of stress among teachers (Ekundayo \& Kolawole, 2013). One of the interesting observed by some of the researchers indicate that male secondary school teachers experience more stress than woman secondary school teachers which results in poor physical health of men as compared to women, studies revealed (Aftab \& Khatoon, 2012). As we all can observe that stress affects the efficiency of the individual.

Another finding has clearly revealed that role ambiguity, poor relations with boss, work overload are the main sources of stress among teachers (Manabete, John, Makinde \& Duwa, 2016). The first step towards tackling stress is to acknowledge its existence. So there is a need to provide proper conducive environment and support to teachers to maintain individual stress at their workplace. Teachers may alter the way to things in optimistic manner which will facilitate them in improving their functional skills and reduce stress. This will ultimately help for higher satisfaction from the profession. Besides that, the institution or management may investigate the causes for stress and evaluate the organizational climate of the school. They can also suggest ways, like workshops and seminars to cope with stress effectively.

There are some other measures which could prove beneficial to teachers in coping with stress like, improve self esteem, build self confidence, develop a good sense of humour, get adequate sleep, practice yoga and meditation, exercise regularly, and foster a supportive friend circle. In 


\section{Stress among Teachers: A Theoretical Examination}

addition to that effective time management among the teachers is also a main strategy towards coping with stress in the work place. These coping strategies go a long way in reducing stressful work situations and improving the effectiveness of the teachers.

\section{Stress and Elementary Teachers}

This section of this review covers the type, level, sources and remedies of the stress experienced by elementary school teachers. Eres \& Atanasoska (2011) carried out a study entitled occupational stress of teachers: a comparative study between Turkey and Macedonia tried to determine stress level of Turkish and Macedonian teachers living in different socio-cultural and economic situations. The results of their study revealed that Turkish teachers have mild stress levels and Macedonian teachers have moderate stress levels. There is a meaningful difference in the stress level points of Turkish and Macedonian teachers. Policy makers are advised to analyse the teacher training and assessment system with the assumption that personal and social characteristics and working conditions may have an effect on teacher stress.

Hasan (2014) studied the occupational stress of primary school teachers of primary government and private school teachers. The findings revealed that primary school teachers have found to be highly stressed. Findings also revealed that the private primary school teachers have also found to be highly stressed in comparison to their government primary school teacher counterparts.

Nobile (2014) investigated the relationships between biographical variables of gender, age, experience, and employment position and occupational stress of staff members in catholic primary schools. They found that age, gender and position were related to three out of the four identified domains of occupational stress as well as overall occupational stress. In addition, male staff experience higher levels of general occupational stress than their female colleague overall. It was recommended by the researcher that there should be a reasonable quantum of research regarding stress of teacher's aid.

Demjaha, Minov, Stoleski, \& Zafirova (2015) investigated the stress causing factors among teachers in elementary schools and their relationship with demographic and job characteristics. The results of the study depicted that the highest levels of perceived teachers' work-related stress were caused by changes in terms and conditions without consultation and given responsibility without the authority to take decisions.

Demjaha, Bislimovska \& Mijakoshi (2015) examined the level of work related stress among teachers in elementary schools. The findings revealed that the majority of interviewed teachers perceived their work-related stress as high or very high. In terms of the relationship between the level of teachers' stress and certain demographic and job characteristics, the level of workrelated stress has shown significantly high relation to gender, age, levels of grades taught as well as working experience, and significant relation to the level of education. 


\section{Stress among Teachers: A Theoretical Examination}

While considering the above findings it would be worth to conclude that occupational stress among elementary school teachers is the result of various factors such as the mind set of being exploited in case of private schools. While comparing it with government school teachers they are less burdened (Hasan, 2014). Besides this some of the researchers have emphasized the relationship between various biographical variables like gender, age, experience and employment position etc. It was found during the research that three out of four variables excluding experience were identified the domains of occupational stress (Nobile, 2014).

Few researchers indicated personal, social characteristics and working conditions as factors of stress on teachers, along with that work related stress were caused due to the changes in terms and conditions without consulting teachers and given them responsibility without authority to take decisions, some studies revealed (Eres \& Atanasoska, 2011)\& (Demjaha, Minov, Stoleski, \& Zafirova2015). So in order to reduce stress among teachers the administration may inform them before given any responsibility and also allow them to take their decisions.

\section{Stress and Teachers in Different Organisation}

This section of this review covers the type, level, sources and remedies of the stress experienced by teachers working in various institutions. Baker, Shammari \& Jefri (1995) examined different Saudi organizations to assess stress levels and their differences with respect to nationality (Saudis, Arabs, Asians and Westerners), type of organization (public, private). The results revealed that the main source of stress for employees working in private organizations is the lack of knowledge about their performance, while this is not the case for employees working in public organizations. Researchers also pointed out that Saudi employees have the highest levels of stress, with Arabs second, Asians third, while Westerners (Europeans and North Americans) registered the lowest levels of stress.

Bashir\& Ramay (2010) investigated the relationship between job stress and job performance on bank employees of banking sector in Pakistan. They found that there was significant negative correlation between job stress and job performances. Results also indicated that job stress significantly reduces the performance of an individual. Researchers suggested that organization may facilitate supportive culture within the working atmosphere of the organization to reduce the unwanted level of stress.

Bakshi \& Kochhar (2011) conducted a research entitled, “A Study of Stress Role on Faculty: An Analysis of Professional Institutions." During their research they tried to find out the factors which are responsible for stress in faculty members of professional institutions. The findings of their study revealed that the factors of their stress caused by due to the interference of the employment organizational responsibilities with their family organizational role, lack of their involvement in decision making that reduced their responsibilities and the participatory model in their organizational set up which enhanced their responsibilities to the point of exhaustion and 


\section{Stress among Teachers: A Theoretical Examination}

also revealed that majority of the faculty members revealed that stress was basically due to their laziness.

Hunnur, \& Bagli, (2014) conducted a study on relationship between occupation stress index dimensions and demographic variables of police sub inspectors and asst. sub inspectors in police department. During Their Research they tried to identify many of the stresses that are placed on police personnel, and various stressors and the relationship between the stress dimensions and the demographic variables like age, education qualification and work experience. The results of their findings indicated that the occupation stress dimensions do not differ significantly on the basis of demographic variables such as age, education qualification, and work experience.

Nirmala, \& Babu (2015) carried out a study on job stress among health care professionals in selected hospitals with special reference to age and gender. They investigated the levels of stress among various health care professionals (doctors, nurses and supporting staff) to identify the difference according to the age groups, gender and marital status. The findings suggested that health care professional's age 41 years feels significantly higher level of job stress when compared to other age groups. Male health care professionals feel significantly high stress when compared to females. According to the marital status, the married health care professionals feel significantly higher level of job stress when compared to unmarried professionals.

While reviewing the above discussed literature regarding stress among different organisations, it can be concluded that the findings of some studies revealed that the factors of organisational stress are the results of interference of employment organisational responsibilities with their family organisational role. It has also been revealed that most of the faculty members signified stress because of their laziness (Bakshi \& Kochhar, 2011). Other studies relating to health care professionals revealed that male health care professionals feel significantly high stress when compared to females (Babu, 2015). Accordingly married health care professionals feel significantly higher level of job stress when compared to unmarried professionals. Some of the researchers indicated that the occupational stress dimension do not differ significantly on the basis of demographic variables such as age, educational qualification and work experience (Hunnur, \& Bagli, 2014). Few studies revealed that the main source of stress for employees working in private organisation is the lack of knowledge of their performance (Baker, Shammari \& Jefri, 1995). It has been also revealed that job stress significantly reduces the performance.

\section{CONCLUSION}

This paper was an attempt to discover the stress levels of the teachers working in various organisations. The paper thoroughly covered stress among teachers Working in University, secondary schools, elementary schools and various other organisations. The studies conducted by the researchers have revealed that the teaching profession is no more the profession of a little stress. Neck to neck competition in all fields is now reality in the era of Globalisation where 
whole world is competing with each other. Researchers have suggested several ways to put check over the unjustified stress to promote sound health and well-being. Future researches may suggest some intervention strategies to manage the stress effectively.

\section{Acknowledgments}

The author appreciates all those who participated in the study and helped to facilitate the research process.

\section{Conflict of Interests}

The author declared no conflict of interests.

\section{REFERENCES}

Aftab, M., \& Khatoon, T. (2012). Demographic Differences and Occupational Stress of Secondary School Teachers. European Scientific Journal, 8(5), 159-175.

Aggarwal, R. (2012). Self-Efficacy as Predictor of Occupational Stress among Academic Faculties of Punjab University and Guru Nanak Dev University. Indian Journal of Psychological Science, 3 (1), 49-61.

Baker, K.A.B., Shammari, A., \& Jefri, O.A. (1995). Occupational stress in different organizations a Saudi Arabian. Journal of Managerial Psychology 10(5), 24-28.

Bakshi, P., \& Kochhar, V. (2011). A study of stress role on Faculty: An Analysis of professional institutions in Haryana. International Journal of Research in IT \& Management, 2(9), 130- 139.

Bashir, U. \& Ramay, M. I. (2010). Impact of Stress on Employees Job Performance A Study on Banking Sector of Pakistan. International Journal of Marketing Studies, 2, (1), 122-126.

Bhuvaneshwari, M. (2013). A Case Study on Psychological and Physical Stress Undergone by Married Working Women. Journal of Business and Management, 14(06), 38-44.

Demjaha, T.A., Bislimovska, J. K., \& Mijakoshi, D. (2015). Level of work related stress among teachers in elementary Schools. Journal of medical sciences, 2 (3), 484-488.

Demjaha, T.A., Minov, J., Stoleski, S., \& Zafirova, B.(2015). Stress Causing Factors among Teachers in Elementary schools and Their Relationship with Demographic and Job Characteristics. Journal of Medical Sciences, 3(3), 493 - 499.

Ekundayo, H.T., \& Kolawole, A.O. (2013). Stress among Secondary School Teachers in Ekiti State, Nigeria. Journal of Educational and Social Research, 3(2), 311- 315.

Eres, F., \& Atanasoska, T. (2011). Occupational Stress of Teachers. A Comparative Study between Turkey and Macedonia. International Journal of Humanities and Social Science, 1(7), 59-65.

Ghania, M. Z., Ahmad, A. C., \& Ibrahim, S. (2014). Stress among Special Education Teachers in Malaysia. Procedia -Social and Behavioural Sciences, 114, 4-13.

Hasan, D. A.(2014). A Study of occupational stress of Primary school teachers. Hasan, A. / Educationia Confab, 3(4), 11-19. 


\section{Stress among Teachers: A Theoretical Examination}

Hunnur, R.R., \& Bagli, M.M. (2014). A Study on Relationship between Occupation Stress Index Dimensions and Demographic Variables of Police Sub Inspectors and Asst. Sub Inspectors in Police Department. International Journal of Business and Administration, 1(3), 161-175.

Kachroo, W. Q. (2014). Stress among adolescents in Jammu and Kashmir. International Journal in Management and Social Science, 2(3), 47-60.

Kousar, T., \& Sohail, T. (2014). Occupational Role Stress and Health related Quality of Life among Secondary School Teachers. Journal of Arts and Social Sciences, 1(1), 9-24.

Manabete, D.S.S., John, C.A., Makinde, A. A., \& Duwa, S.T. (2016). Job Stress among School Administrators' and Teachers in Nigerian Secondary Schools and Technical Colleges. International Journal of Education, Learning and Development, 4(2), 9-24.

Nagra, V., \& Arora, S. (2013). Occupational Stress and Health Among Teacher Educators. International Journal of Advanced Research in Management and Social Sciences, 2 (8), 1-13.

Nirmala, K.V., \& Babu, M.S. (2015). Job Stress among Health Care Professionals in Selected Hospitals with Special Reference to Age and Gender. International Journal of Science and Research, 4(6), 1625-1629.

Nobile, J.J.D. (2014). Occupational stress of Catholic primary school staff: a study of biographical differences. International Journal of Educational Management, 24(6), 492-506.

Onifade ,A. (2000). Determinants of Occupational Stress and Coping Strategies of Physical Education Teachers. Ghana Educational Media and Technology Association Journal. 04, 1-115.

Reddy, G. L., \& Anuradha, R.V. (2013).Occupational Stress of Higher Secondary TeachersWorking in Vellore District. International Journal of Educational Planning \& Administration, 2(3), 9-24.

Shikieri, A.B.E., \& Musa, H.A. (2012). Factors Associated With Occupational Stress and Their Effects on Organizational Performance in a Sudanese University. Scientific Research Journal, 3(1), 134-144.

Sindhu, K.P. (2014). A Study on Stressors among College Teachers. Journal of Business and Management, 16(7), 37-4.

Wen, C. K. (2009). A study of stress sources among college students in Taiwan. Journal of Academic and Business Ethics, 1, 1-8.

How to cite this article: W Parrav, S Kumar, P Awasthi (2016), Stress among Teachers: A Theoretical Examination, International Journal of Indian Psychology, Volume 3, Issue 4, No. 57, ISSN 2348-5396 (e), ISSN: 2349-3429 (p), DIP: 18.01.029/20160304, ISBN: 978-1-365-239939 